\title{
Music and social bonding: "self-other" merging and neurohormonal mechanisms
}

\author{
Bronwyn Tarr*, Jacques Launay and Robin I. M. Dunbar \\ Social and Evolutionary Neuroscience Research Group, Department of Experimental Psychology, University of Oxford, Oxford, UK
}

\author{
Edited by: \\ Guy Madison, Umeå University, \\ Sweden \\ Reviewed by: \\ Elizabeth Hellmuth Margulis, \\ University of Arkansas, USA \\ Guy Madison, Umeå University, \\ Sweden

\section{${ }^{*}$ Correspondence:} \\ Bronwyn Tarr, Social and Evolutionary \\ Neuroscience Research Group, \\ Department of Experimental \\ Psychology, University of Oxford, \\ Tinbergen Building, Oxford OX1 3UD, \\ UK \\ e-mail: bronwyn.tarr@psy.ox.ac.uk
}

It has been suggested that a key function of music during its development and spread amongst human populations was its capacity to create and strengthen social bonds amongst interacting group members. However, the mechanisms by which this occurs have not been fully discussed. In this paper we review evidence supporting two thus far independently investigated mechanisms for this social bonding effect: self-other merging as a consequence of inter-personal synchrony, and the release of endorphins during exertive rhythmic activities including musical interaction. In general, self-other merging has been experimentally investigated using dyads, which provide limited insight into largescale musical activities. Given that music can provide an external rhythmic framework that facilitates synchrony, explanations of social bonding during group musical activities should include reference to endorphins, which are released during synchronized exertive movements. Endorphins (and the endogenous opioid system (EOS) in general) are involved in social bonding across primate species, and are associated with a number of human social behaviors (e.g., laughter, synchronized sports), as well as musical activities (e.g., singing and dancing). Furthermore, passively listening to music engages the EOS, so here we suggest that both self-other merging and the EOS are important in the social bonding effects of music. In order to investigate possible interactions between these two mechanisms, future experiments should recreate ecologically valid examples of musical activities.

\section{Keywords: music, rhythm, social bonding, endorphins, self-other merging, synchrony}

\section{INTRODUCTION}

Music-making, and movement to music, are activities central to ritual, courtship, identity, and human expression cross-culturally. Based on this ubiquity, it is argued that music has played an important role during our evolutionary history (Cross, 2001; Huron, 2001; McDermott, 2008; Dunbar, 2012b; although see, Pinker, 1997 for an alternative perspective).Whilst sexual selection and courtship are proposed as partial explanations for the widespread appreciation and aptitude for music (Brown, 2000; Merker, 2000; Miller, 2000 for a critique), there are other suggestions regarding its positive role for human societies. In this review we focus on the fact that in almost all cultures globally, and throughout history, music is a social activity (Nettl, 1983, 2000) that involves movement to rhythmic sound and plays a significant role both in creating social bonds (Roederer, 1984; McNeill, 1995; Freeman, 2000; Dunbar, 2004) and indicating coalition strength (Hagen and Bryant, 2003). This effect of musical activity on "social bonding" (the psychological experience of increased social closeness, reflected in prosocial behaviors) may be responsible for the widespread occurrence of musical activities and may have played an important role in the evolution of human sociality (Dunbar, 2012a,b).

While there has been much interest in the relationship between music and social bonding, there is as yet no consensus about the mechanisms by which this might occur. Many aspects of musicmaking which make people feel socially close are not specific to music-based activities, such as sharing attention with co-actors (e.g., Reddy, 2003), working toward similar goals (e.g., Tomasello et al., 2005), and experiencing a sense of positivity after successful co-engagement (e.g., Isen, 1970). An important feature that distinguishes musical activities from other social behavior is the importance of shared rhythms, and the externalization of predictable rhythms that allow synchronization to occur between two or more people (e.g., Bispham, 2006; Merker et al., 2009). Furthermore, people attribute movement and human agency to musical sound (e.g., Cross, 2001), which influences how synchronization occurs (Launay et al., 2013, 2014) as well as impacting upon affective experience (e.g., Fritz etal., 2013a). Here we focus on two proposed mechanisms of social bonding: self-other merging as a consequence of interpersonal synchrony, and the release of endorphins during synchronized exertive movements. We bring together evidence that both pathways from musicmaking to social bonding are relevant, highlight connections between the two, and suggest that both should be included in any account of how people form and maintain social bonds through music-making.

Firstly, performing movements simultaneously with someone else, (i.e., synchronizing), is believed to cause some blurring of self and other via neural pathways that code for both action and perception (Overy and Molnar-Szakacs, 2009). Secondly, it has been argued that group music-making leads to social bonding due to the release of neurohormones, specifically oxytocin (e.g., 
Freeman, 2000; Huron, 2001; Grape et al., 2003). The oxytocin account relies on its action as a social neurohormone in a range of mammals (e.g., Insel, 2010), and the suggestion that musicmaking (which involves sensory overload, physical activity, strong emotional arousal and social behavior) is particularly conducive to oxytocin release (e.g., Freeman, 2000). Whilst elevated oxytocin levels has been linked to increased trust (Kosfeld et al., 2005; Zak et al., 2005), eye contact (Guastella et al., 2008), face memory (Savaskan et al., 2008), generosity (Zak et al., 2007), empathy and the ability to infer the mental state of others (Domes et al., 2007), the causal link between music-related physical experience and oxytocin described by Freeman is tenuous. Here we review the evidence that the endogenous opioid system (EOS), and particularly endorphins, play a central role in the maintenance of non-sexual, non-kinship social bonds (Machin and Dunbar, 2011) that are characteristic of group musical activities. Given that endorphins are argued to mediate the pleasure experienced when listening to music (e.g., Huron, 2006; Koelsch, 2010) and recent evidence demonstrates that endorphins are released during synchronized and exertive activity (Cohen et al., 2010; Sullivan and Rickers, 2013; Sullivan et al., 2014), we argue that this particular peptide is an important candidate for the neurohormonal underpinnings of social bonding during group musical activities.

To begin, we will explore the evidence linking synchronization and social bonding, and subsequently the particular role of selfother merging, which may occur via shared neural pathways for action and perception. Following this we review evidence of the EOS's role in social bonding, and discuss the case for this mechanism in musical activities. Finally we highlight the importance of using ecologically valid musical contexts in future investigation into the possible relationship between the two mechanisms that underpin the relationship between music and social bonding.

\section{SYNCHRONIZATION AND SOCIAL BONDING}

Synchronization is often cited as an important mechanism by which social bonding can occur (Hove and Risen, 2009; Wiltermuth and Heath, 2009; Valdesolo and Desteno, 2011; Launay et al., 2013). This proposition builds in part on an identified relationship between mimicry (i.e., making a similar movement to another individual) and positive social behavior, such as self-reported rapport between two individuals (e.g., LaFrance and Broadbent, 1976; LaFrance, 1979). Mimicry improves rapport between people (Chartrand and Bargh, 1999; Lakin and Chartrand, 2003), which in turn influences the amount of mimicry that people perform (Van Baaren et al., 2004; Stel et al., 2010), thereby causing a positive feedback loop in which people can become increasingly socially close to one another through making similar movements, and more inclined to continue making similar movements once social closeness is established. Synchrony, like mimicry, involves simultaneous movements with another individual, with the additional element of rhythmically matched timing, which requires the prediction of movements of co-actors. Consequently, synchronization is likely to have similar or more pronounced effects on social bonding than mimicry.

People tend to spontaneously and unintentionally synchronize movements with one another, even to some extent when instructed not to do so (Issartel et al., 2007; Oullier et al., 2008; van Ulzen et al., 2008). Those with pro-social tendencies exhibit more spontaneous synchronization than those with pro-self tendencies (Lumsden et al., 2012), and the desirability of a partner can influence whether synchrony occurs (Miles et al., 2010, 2011), suggesting that this is a social behavior, rather than an automatic motor process. Perception of synchrony is also interpreted as a signal of rapport for both basic sounds (e.g., sound of people walking together: Miles et al., 2009; Lakens and Stel, 2011), and more complex musical stimuli (Hagen and Bryant, 2003).

More importantly, there is evidence that synchronization between people can influence their subsequent positive social feelings toward one another. This has been demonstrated in a number of experimental studies, involving participants tapping synchronously with an experimenter (Hove and Risen, 2009; Valdesolo and Desteno, 2011), walking in time with other people (Wiltermuth and Heath, 2009; Wiltermuth, 2012), dancing together (Reddish et al., 2013), and even when people have no visual access to one another but are synchronizing with the sounds of another person (Kokal et al., 2011; Launay et al., 2014).

The likely importance of social bonding via synchrony in musicbased activities draws on the observation that beyond a tendency to synchronize with one another, humans have a culturally ubiquitous aptitude for entrainment to rhythmic beats (Clayton et al., 2005; Brown and Jordania, 2011), particularly those embedded in music (e.g., Demos etal., 2012). However, the source and context associated with those rhythms are paramount. For example, Kirschner and Tomasello (2009) demonstrated that children's synchronization with a beat is improved in the presence of a person compared to when interacting solely with an isochronously beating drum. This suggests that from a young age, the awareness of agency related to perceived sound (and belief that the sound is produced by the intentional movements of another person) encourages synchronization with that sound, thereby likely influencing the social bonding effects of musical activities. Agent-driven sounds, and the associated perception of movement of another person, engage motor regions in the listener's brain, potentially resulting in "self-other merging," which has been argued to arise when individuals experience their movement simultaneously with another's.

\section{SELF-OTHER MERGING AND SOCIAL BONDING}

When moving at the same time as others we experience some co-activation of neural networks that relate to movement of self (as action), and other (as perception; e.g., Overy and MolnarSzakacs, 2009). There is much recent research investigating the relationship between perception and action (Buccino et al., 2001; Fadiga et al., 2002; Rizzolatti, 2005; Caetano et al., 2007), which has identified "mirror neurons" in macaques (Gallese et al., 1996; Rizzolatti etal., 1996) that selectively respond to the macaque's own movement and perception of the goal-directed movement of others. While there is no evidence for neurons with equivalent selectivity in humans (Hickok, 2009), this research led to much interest into how perception of goaldirected movement can engage regions of the brain related to making similar movements (Rizzolatti, 2005). Importantly 
it is now well recognized that perceiving the actions of another person can lead to activation of the same neural motor networks involved in making those actions oneself (e.g., Fadiga et al., 1995).

When our own actions match those of another's, it is possible that the intrinsic and extrinsic engagement of neural actionperception networks make it difficult to distinguish between self and perceived other, thus creating at least a transient bond between the two (Decety and Sommerville, 2003; Sebanz et al., 2006; Sommerville and Decety, 2006; Knoblich and Sebanz, 2008; Marsh et al., 2009; Overy and Molnar-Szakacs, 2009). A well replicated experimental example of this is the rubber hand illusion (Botvinick and Cohen, 1998). In this paradigm, a participant's arm is hidden from sight, and a replacement rubber arm is visible where their own arm is expected. While they view the rubber hand being touched with a paintbrush, their own (hidden) hand is simultaneously touched with a paintbrush, with synchronized strokes. This matching of visual and tactile input leads to an increased subjective sense that the rubber hand is part of the participant's body. The effect disappears when the two inputs are not synchronized. This provides evidence that selfother blurring is possible even with an inanimate object, and some aspects of this are likely to apply to human-human synchronized interaction. Indeed, behavioral synchrony has also been demonstrated to induce common neural signatures between interacting agents (Oullier etal., 2005; Tognoli et al., 2007; Lindenberger et al., 2009; Dumas et al., 2010). However, evidence for common neural signatures during synchronization should be interpreted with caution, as it can only indicate that similar cortical networks are involved in making the same movements for different people.

Researchers who argue that self-other merging is an important part of the bonding effects of synchronization primarily draw support from dyadic experiments in which participants' actions are perceived to occur at the same time as one another. Theoretically, dyads are capable of achieving synchrony with relative ease simply because there is only one other person to keep track of. As such, synchrony is reasonably attainable, and associated selfother merging (and bonding) effects are likely to be achieved fairly easily.

Musical activities, on the other hand, are not limited to one-on-one interactions, and have historically involved groups (Nettl, 1983, 2000). With large numbers of people, it is difficult to simultaneously observe the movements of all the other participants, making self-other merging a less likely prospect. Rhythm provides an external, predictable scaffolding that can facilitate synchrony with both the music, and by extension, aids synchrony between individuals engaging in the same musical experience. A recent experiment involved people rocking on rocking chairs with one another, while music played in the room or did not (Demos etal., 2012). While self-reported rapport between co-actors correlated with synchronization achieved with the music, rapport did not correlate with synchronization that occurred between co-actors. This implies that externalizing the target of synchrony (e.g., to music) allows bonding with other people present, in the absence of explicit synchrony between those people. This finding has important implications given that group musical activities often involve non-identical movements between people (making self-other merging an unlikely prospect).

Given that the self-other merging account of social bonding relies on simultaneous, similar movements, it is likely that this mechanism does not provide a complete account for the bonding that arises in large group situations. Additional mechanisms need to be considered, in particular mechanisms that underpin the social bonding associated with musical activities. One likely mechanism involves the EOS, and particularly endorphins, which are released through synchronous and exertive activities, and during passive engagement with music, and play a central role in social bonding among primate species (e.g., Keverne et al., 1989).

\section{ENDORPHINS AND SOCIAL BONDING}

Investigation into the neuropeptide underpinnings of social bonding have implicated neurohormonal cascades involving oxytocin and vasopressin (e.g., Carter, 1998), dopamine and serotonin (e.g., Depue and Morrone-Strupinsky, 2005), and endorphins released by the EOS (Curley and Keverne, 2005; Dunbar, 2010). Recently, oxytocin has been promoted as the social neurohormone (Bartz et al., 2011; Meyer-Lindenberg et al., 2011), largely due to evidence from pair-bonding and mother-infant bonding (e.g., Atzil et al., 2011; Feldman, 2012). However, despite apparent interactions between opioids (specifically endorphins) in the bonding activity of oxytocin (e.g., Depue and MorroneStrupinsky, 2005), and evidence of the EOS's role in primate pair-bonding (Ragen et al., 2013), maternal care (Martel et al., 1993), as well as empirical evidence that increased opioid levels are associated with social grooming and affiliative behaviors in non-sexual, non-kin related conspecifics (Keverne et al., 1989; Schino and Troisi, 1992; Martel et al., 1995), the role of the EOS in social bonding remains relatively underexplored, possibly due to the difficulties in measuring endorphin titres directly (Dearman and Francis, 1983).

The EOS consists of opioid receptors and associated ligands distributed throughout the central nervous system and peripheral tissues, such as the nucleus accumbens (Fields, 2007; Trigo et al., 2010). The EOS is central in opioid-mediated reward (Koob, 1992; Olmstead and Franklin, 1997; Comings et al., 1999), social motivation (Chelnokova et al., 2014), and pleasure and pain perception (Janal et al., 1984; Leknes and Tracey, 2008). Elevated opioid levels are correlated with feelings of euphoria (Boecker et al., 2008), and Koepp et al. (2009) report activation of general opioid receptors in the hippocampus and amygdala in response to positive affect. Deactivation of certain opioid receptor sites has been associated with negative affect (Zubieta et al., 2003).

The possible role of the EOS in social bonding is formalized in the brain opioid theory of social attachment (BOTSA). BOTSA is based on evidence of behavioral and emotional similarities between those in intense relationships, and those addicted to narcotics (Insel, 2003). Furthermore, endogenous opioids, particularly endorphins, are related to social bonding in many non-human animals such as rhesus macaques (Schino and Troisi, 1992; Graves et al., 2002), other monkeys (Keverne et al., 1989; Martel etal., 1995; Ragen etal., 2013), voles (Resendez et al., 2013), puppies, rats and chicks (Panksepp etal., 1980), and 
mammals generally (Broad et al., 2006). Given the role of endorphins in bonding in other species, it is plausible that the EOS may also underpin human social bonds (Matthes et al., 1996; Moles etal., 2004; Depue and Morrone-Strupinsky, 2005; Dunbar, 2010).

Opioids are released in response to low levels of muscular and psychological stress (Howlett et al., 1984), for example during exercise (Harbach et al., 2000). Positron emission tomography (PET) scans have confirmed the euphoric state that follows exercise (termed "runner's high") is due to endogenous opioids (Boecker etal., 2008). Further to the effect on mood, opioids have an analgesic effect (Van Ree et al., 2000), and much evidence suggests that endorphins are central in the pain management system (D’Amato and Pavone, 1993; Benedetti, 1996; Zubieta et al., 2001; Fields, 2007; Bodnar, 2008; Dishman and O'Connor, 2009; Mueller et al., 2010). Given that direct measures of endogenous opioids are costly and invasive (Dearman and Francis, 1983), pain threshold is a commonly used proxy measure of endorphin release, and this has been operationalised using the length of time holding a hand in ice water (Dunbar et al., 2012a,b), a ski exercise (maintaining a squat position with legs at right angles: Dunbar et al., 2012a), an electrocutaneous simulator (Jamner and Leigh, 1999), pressure produced using a blood pressure cuff (Cogan et al., 1987; Cohen et al., 2010; Dunbar et al., 2012a,b), and the amount of pain medication requested by patients (Zillmann et al., 1993).

According to pain threshold assays, various exertive human social bonding activities, such as laughter (Dezecache and Dunbar, 2012; Dunbar et al., 2012a), group synchronized sport (Cohen et al., 2010; Sullivan and Rickers, 2013), and singing and dance (Dunbar et al., 2012b), trigger endorphin release. Specifically, synchronized exertive activity (such as rowing) elevates pain thresholds significantly more than non-synchronized exertion (Sullivan and Rickers, 2013; Sullivan et al., 2014), suggesting that rhythmic, music-based activities may similarly facilitate endorphin release.

\section{ENDORPHINS AND MUSIC}

Based on the association between exertion and endorphin release, a number of studies have investigated the effect of active engagement in musical activities (i.e., involving overt movement) and the EOS (see Table 1). For example, sufficiently vigorous singing, dancing, and drumming trigger a significantly larger increase in pain threshold and positive affect compared to listening to music and engaging in low energy musical activities (Dunbar et al., 2012b). In a recent set of studies, exercise machines were linked to musical output software such that individuals "created" music as they exerted themselves (Fritz et al., 2013a,b). These experiments demonstrated that when movement (during group exercise) results in musical feedback, participants perceived exertion to be lower (Fritz et al., 2013b), reported enhanced mood, and felt a greater desire to exert themselves further (Fritz et al., 2013a), in comparison to when they were exercising whilst listening (passively) to independently provided music. As such, perception of agency in a musical setting is associated with greater endorphin activation and may therefore lead to greater effects in terms of mood and ability to withstand strenuous exercise.

However, activation of the EOS through music is not limited exclusively to situations involving exertion (see Table 1). Listening to music reportedly helps to manage pre-operative hypertension and psychological stress (Allen et al., 2001), reduces sedative requirements during spinal anesthesia (Lepage et al., 2001) and other surgical procedures (Koch et al., 1998), decreases perception of pain (Good et al., 2001; Nilsson et al., 2003) thereby diminishing the need for opioid agonists following operative care (Cepeda et al., 2006; Bernatzky et al., 2011), and improves post-operative recovery (Nilsson et al., 2001). Many of the experiments in this area directly attribute these results to the EOS, and given the strong role of opioid receptor activation in analgesia (Leknes and Tracey, 2008), the body of work linking music and pain may generally be considered convincing evidence of the role of opioid activation.

Table 1 | Summary of studies providing evidence for the role of EOS in music-related activities.

\begin{tabular}{|c|c|c|}
\hline & Passive listening & Active engagement \\
\hline Pain threshold, pain & Post-operative pain: Koch etal. (1998), Allen etal. (2001), Good et al. (2001), Lepage & Singing, drumming, dance: Dunbar \\
\hline management & etal. (2001), Nilsson etal. (2001, 2003), Nilsson (2008), Bernatzky etal. (2011) for a & etal. (2012b) \\
\hline & review see Cepeda etal. (2006) & \\
\hline \multirow[t]{3}{*}{ Brain activation regions } & EOS, pleasure, and reward circuits: Blood and Zatorre (2001), Stefano et al. (2004), & \\
\hline & Menon and Levitin (2005) & \\
\hline & Nucleus accumbens and pleasure states: Koelsch (2014) & \\
\hline \multirow[t]{3}{*}{ Emotions and mood } & Techno-music: Gerra et al. (1998) & Increased positive affect: Dunbar et al. \\
\hline & Emotional effects of music: Koelsch (2010) & $(2012 b)$ \\
\hline & Positive affect: Huron (2006) & Enhanced mood: Fritz et al. (2013a) \\
\hline \multirow[t]{2}{*}{ Health } & Lower blood pressure and relaxation: Chiu and Kumar (2003), Stefano etal. (2004) & \\
\hline & Anxiolytic music: McKinney et al. (1997b) & \\
\hline Other & Musical "thrills": Goldstein (1980), Panksepp (1995), Menon and Levitin (2005) & $\begin{array}{l}\text { Perception of exertion and desire to } \\
\text { exert oneself: Fritz et al. (2013b) }\end{array}$ \\
\hline
\end{tabular}


Positron emission tomography (PET) and functional magnetic resonance imaging (fMRI) research also provide evidence that passive listening to music activates the EOS and brain areas associated with pleasure and reward (Blood and Zatorre, 2001; Stefano et al., 2004). For example, recent evidence that music listening is associated with activation in areas such as the nucleus accumbens (Brown et al., 2004; Menon and Levitin, 2005; Koelsch, 2014), the high number of opioid receptors in this region (Fields, 2007; Trigo et al., 2010) and the role of opioids in mood and pleasure states (Berridge and Kringelbach, 2008) provide support for the theory that the EOS is involved in music listening.

The importance of the EOS in regulating affective experiences in response to music (Zubieta et al., 2003) is further supported by evidence linking music induced "thrills" to endorphin activation (Goldstein, 1980), and the EOS's association with reward circuits (Menon and Levitin, 2005). In addition, the sense of elation that arises when engaging in musical activities has been attributed to endorphin release (Chiu and Kumar, 2003; Huron, 2006; Dunbar, 2009). Calming music is thought to act via the EOS by buffering the effect of stressful events (see McKinney etal., 1997b for a review), and relaxation following music listening is also linked to the EOS (Stefano et al., 2004). Gerra et al. (1998) report that listening to techno-music significantly changes emotional states (and increases beta-endorphin levels), due to its strong rhythmic beat and engagement of motor regions of the brain. Activation of the EOS, and its role in various affective, calming and analgesic effects, is therefore evident in cases of passive music listening, although a systematic investigation of this effect is still lacking.

It is important to note that there is also some evidence indicating that neurohormones other than endorphins are involved during music-based activities (e.g., Grape et al., 2003; BachnerMelman et al., 2005; Chanda and Levitin, 2013). In a recent review, Chanda and Levitin (2013) highlight evidence suggesting that stress and arousal effects associated with music-based activities can be linked to cortisol, corticotrophin-releasing hormone and adrenocorticotropic hormone (e.g., McKinney et al., 1997a; Gerra et al., 1998). Various immunity benefits of music have been attributed to, inter alia, cortisol (e.g., Beck et al., 2000; Kuhn, 2002), cytokinin (e.g., Stefano et al., 2004), and growth hormones (e.g., Gerra et al., 1998). Finally, dopamine is key in reward and motivation circuits during musical activities (e.g., Salimpoor et al., 2011), which are likely to interact synergistically with the EOS in mediating the pleasure states associated with music (Chanda and Levitin, 2013). While we argue for further investigation of the EOS as a potential mediator of the positive social effects of musical engagement, it may be difficult to separate out the role of this hormone from other neurochemicals involved in these experiences.

As indicated by the evidence reviewed above, the way that we experience music, whether during passive listening or active engagement, appears to involve the EOS, and endorphins specifically. In the following section we discuss how both self-other merging and the EOS mechanisms might underpin our musical experiences.

\section{FROM MUSIC TO SOCIAL BONDING}

Both self-other merging and the EOS help explain the subjective experience of social bonding that can arise during musical activities, as illustrated by Figure 1. However, as these two mechanisms have thus far been independently investigated, the interplay between them remains unclear.

As mentioned previously, dyads are capable of achieving synchrony with relative ease (even without music), while in larger groups, synchrony is facilitated via rhythmic scaffolding. Additionally, as music encourages movement (Janata and Grafton, 2003; Madison, 2006; Madison et al., 2011; Janata et al., 2012) by engaging motor regions of the brain (Levitin and Menon, 2003), we might expect engagement with musical sounds to be more exertive than with non-musical sounds. The combination of larger movements and the externalization of the target of synchrony likely facilitates synchronization.

Exertive movements cause affiliative sentiments and behaviors (e.g., Mueller et al., 2003), have effects on mood and emotion (e.g., Karageorghis and Terry, 2009), and, in combination with synchrony, can elevate pain thresholds (e.g., Cohen et al., 2010). These phenomena are all strongly associated with the EOS (e.g., Dishman and O'Connor, 2009). Accordingly, we propose that selfother matching and activation of the EOS are interconnected in explaining the bonding effects that arise during active engagement in group music-based activities, with a possibility that the EOS underpins the psychological experience of self-other merging.

In terms of passive listening to music, the literature reviewed here suggests that the EOS is likely to play a role also in the

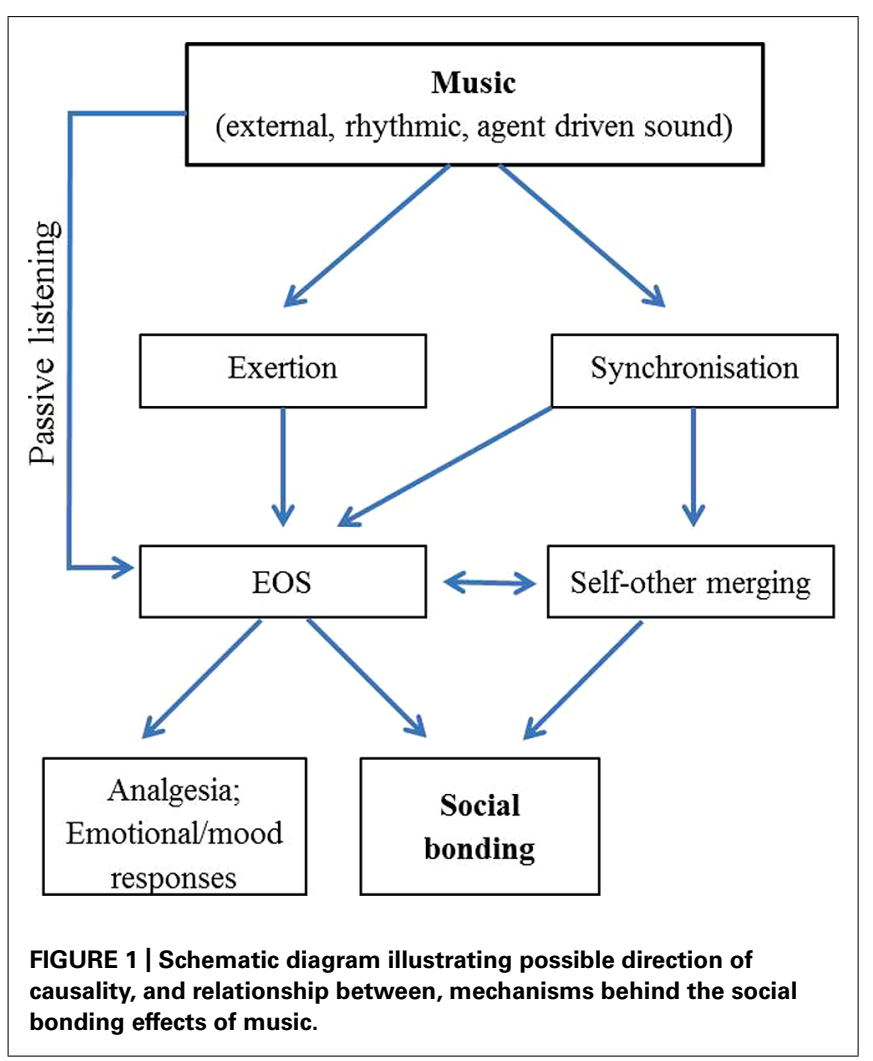


absence of explicit movement and self-other merging during synchrony. Dynamic attending theory (e.g., Jones and Boltz, 1989) suggests that through monitoring of events occurring with predictable temporal patterns we can become entrained to those events. This rhythmic predictability has been suggested to play a key role in the pleasure experienced when listening to music, which may be mediated by the release of endorphins (Huron, 2006; Margulis, 2013). The effect of tempo on arousal (Husain etal., 2002) and the strong ability for music to alter mood (Thayer etal., 1994) and motivational states (Frijda and Zeelenberg, 2001) are both congruous with evidence that EOS activation occurs in the brain when listening and entraining to music (Blood and Zatorre, 2001; Stefano et al., 2004; Menon and Levitin, 2005). Sievers et al. (2013) demonstrate that movement and music are processed crossmodally, as are the emotions expressed through movement and music. Elements of music significantly affect various dimensions of imagery relating to motion (Eitan and Granot, 2006), and listening to music may itself induce thoughts about movement, whether conscious or subconscious (Chen et al., 2008; Levitin and Tirovolas, 2009; Clarke, 2011). Through activation of motor regions of the brain during music listening (Levitin and Menon, 2003), passive engagement with music likely triggers the same neural pathways involved in active engagement (i.e. movement) to music, including pathways implicating the EOS. This activity in motor regions of the brain during music perception is likely to underlie the self-reported experience of "embodied movement" even when listening and not moving to music (e.g., Peters, 2010).

\section{CONCLUSION}

While most accounts of the relationship between music and social bonding have focused separately on self-other merging via synchrony or neurohormonal mechanisms, here we suggest that associations between the two need to be considered, especially when assessing large-scale musical activities. Future work should be directed toward ecologically valid musical experiences involving groups of people interacting with one another rather than dyadic interaction, exertive movements rather than small movements, and movements that are temporally co-ordinated rather than synchronized per se. Using these forms of musical activity it will become possible to explore the relative importance of self-other matching and EOS in music-based activities (including passive listening). Given that humans have significantly larger and more complex social networks than our primate cousins, research in this field will elucidate the means by which our species has the capacity to bond with large groups of conspecifics at the same time. It is likely that some combination of endorphin release and self-other merging lead to the social bonding effects of music, although the relationship between the two mechanisms remains to be sufficiently explored.

\section{ACKNOWLEDGMENTS}

We would like to thank the European Research Council (Grant Number 295663) for its funding support during the writing of this article, and Cole Robertson for commenting on a draft of this manuscript.

\section{REFERENCES}

Allen, K., Golden, L. H., Izzo, J. L., Ching, M. I., Forrest, A., Niles, C. R., et al. (2001). Normalization of hypertensive responses during ambulatory surgical stress by perioperative music. Psychosom. Med. 63, 487-492. doi: 10.1097/00006842-200105000-00019

Atzil, S., Hendler, T., and Feldman, R. (2011). Specifying the neurobiological basis of human attachment: brain, hormones, and behavior in synchronous and intrusive mothers. Neuropsychopharmacology 36, 2603-2615. doi: 10.1038/npp. 2011.172

Bachner-Melman, R., Dina, C., Zohar, A. H., Constantini, N., Lerer, E., Hoch, S., et al. (2005). AVPR1a and SLC6A4 gene polymorphisms are associated with creative dance performance. PLoS Genet. 1:e42. doi: 10.1371/journal.pgen.0010042

Bartz, J. A., Simeon, D., Hamilton, H., Kim, S., Crystal, S., Braun, A., et al. (2011). Oxytocin can hinder trust and cooperation in borderline personality disorder. Soc. Cogn. Affect. Neurosci. 6, 556-563. doi: 10.1093/scan/nsq085

Beck, R. J., Cesario, T. C., Yousefi, A., and Enamoto, H. (2000). Choral singing, performance perception, and immune system changes in alivary immunoglobulin a and cortisol. Music Percept. Interdiscip. J. 18, 87-106. doi: 10.2307/402 85902

Benedetti, F. (1996). The opposite effects of the opiate antagonist naloxone and the cholecystokinin antagonist proglumide on placebo analgesia. Pain 64, 535-543. doi: 10.1016/0304-3959(95)00179-4

Bernatzky, G., Presch, M., Anderson, M., and Panksepp, J. (2011). Emotional foundations of music as a non-pharmacological pain management tool in modern medicine. Neurosci. Biobehav. Rev. 35, 1989-1999. doi: 10.1016/j.neubiorev.2011.06.005

Berridge, K. C., and Kringelbach, M. L. (2008). Affective neuroscience of pleasure: reward in humans and animals. Psychopharmacology (Berl.) 199, 457-480. doi: 10.1007/s00213-008-1099-6

Bispham, J. (2006). Rhythm in music: what is it? Who has it? And why? Music Percept. 24, 125-134. doi: 10.1525/mp.2006.24.2.125

Blood, A. J., and Zatorre, R. J. (2001). Intensely pleasurable responses to music correlate with activity in brain regions implicated in reward and emotion. Proc. Natl. Acad. Sci. U.S.A. 98, 11818-11823. doi: 10.1073/pnas.191355898

Bodnar, R. J. (2008). Endogenous opiates and behavior: 2007. Peptides 29, 22922375. doi: 10.1016/j.peptides.2008.09.007

Boecker, H., Sprenger, T., Spilker, M. E., Henriksen, G., Koppenhoefer, M., Wagner, K. J., et al. (2008). The runner's high: opioidergic mechanisms in the human brain. Cereb. Cortex 18, 2523-2531. doi: 10.1093/cercor/bhn013

Botvinick, M., and Cohen, J. (1998). Rubber hands "feel” touch that eyes see. Nature 391:756. doi: 10.1038/35784

Broad, K. D., Curley, J. P., and Keverne, E. B. (2006). Mother-infant bonding and the evolution of mammalian social relationships. Philos. Trans. R. Soc. Lond. B Biol. Sci. 361, 2199-2214. doi: 10.1098/rstb.2006.1940

Brown, S. (2000). "Evolutionary models of music: from sexual selection to group selection," in Perspectives in Ethology, eds F. Tonneau and N. S. Thompson (New York: Plenum), 221-281.

Brown, S., and Jordania, J. (2011). Universals in the world's musics. Psychol. Music 41, 229-248. doi: 10.1177/0305735611425896

Brown, S., Martinez, M. J., and Parsons, L. M. (2004). Passive music listening spontaneously engages limbic and paralimbic systems. Neuroreport 15, 20332037. doi: 10.1097/00001756-200409150-00008

Buccino, G., Binkofski, F., Fink, G. R., Fadiga, L., Fogassi, L., Gallese, V., et al. (2001). Action observation activates premotor and parietal areas in a somatotopic manner: an fMRI study. Eur. J. Neurosci. 13, 400-404. doi: 10.1111/j.1460-9568.2001.01385.x

Caetano, G., Jousmäki, V., and Hari, R. (2007). Actor's and observer's primary motor cortices stabilize similarly after seen or heard motor actions. Proc. Natl. Acad. Sci. U.S.A. 104, 9058-9062. doi: 10.1073/pnas.0702453104

Carter, C. S. (1998). Neuroendocrine perspectives on social attachment and love. Psychoneuroendocrinology 23, 779-818. doi: 10.1016/S0306-4530(98)00055-9

Cepeda, M. S., Carr, D. B., Lau, J., and Alvarez, H. (2006). Music for pain relief (review). Cochrane Database Syst. Rev. CD004843. doi: 10.1002/14651858.CD004843.pub2

Chanda, M. L., and Levitin, D. J. (2013). The neurochemistry of music. Trends Cogn. Sci. 17, 179-193. doi: 10.1016/j.tics.2013.02.007

Chartrand, T. L., and Bargh, J. (1999). The chameleon effect: the perceptionbehavior link and social interaction. J. Pers. Soc. Psychol. 76, 893-910. doi: 10.1037/0022-3514.76.6.893 
Chelnokova, O., Laeng, B., Eikemo, M., Riegels, J., Løseth, G., Maurud, H., et al. (2014). Rewards of beauty: the opioid system mediates social motivation in humans. Mol. Psychiatry 19, 746-747. doi: 10.1038/mp.2014.1

Chen, J. L., Penhune, V. B., and Zatorre, R. J. (2008). Listening to musical rhythms recruits motor regions of the brain. Cereb. Cortex 18, 2844-2854. doi: $10.1093 /$ cercor/bhn042

Chiu, P., and Kumar, A. (2003). Music therapy: loud noise or soothing notes. Int. Pediatr. 18, 204-208.

Clarke, E. F. (2011). "Music perception and musical consciousness," in Music and Consciousness: Philosophical, Psychological, and Cultural Perspectives, eds D. Clarke and E. F. Clarke (New York: Oxford University Press), 193-213.

Clayton, M., Sager, R., and Will, U. (2005). In time with the music: the concept of entrainment and its significance for ethnomusicology. Eur. J. Soc. Psychol. 11, 3-142.

Cogan, R., Cogan, D., Waltz, W., and McCue, M. (1987). Effects of laughter and relaxation on discomfort thresholds. J. Behav. Med. 10, 139-144. doi: 10.1007/BF00846422

Cohen, E. E. A., Ejsmond-Frey, R., Knight, N., and Dunbar, R. I. M. (2010). Rowers' high: behavioural synchrony is correlated with elevated pain thresholds. Biol. Lett. 6, 106-108. doi: 10.1098/rsbl.2009.0670

Comings, D. E., Blake, H., Dietz, G., Gade-Andavolu, R., Legro, R. S., Saucier, G., etal. (1999). The proenkephalin gene (PENK) and opioid dependence. Neuroreport 10, 1133-1135. doi: 10.1097/00001756-19990406000042

Cross, I. (2001). Music, cognition, culture, and evolution. Ann. N. Y. Acad. Sci. 930, 28-42. doi: 10.1111/j.1749-6632.2001.tb05723.x

Curley, J. P., and Keverne, E. B. (2005). Genes, brains and mammalian social bonds. Trends Ecol. Evol. 20, 561-567. doi: 10.1016/j.tree.2005 05.018

D'Amato, F. R., and Pavone, F. (1993). Endogenous opioids: a proximate reward mechanism for kin selection? Behav. Neural Biol. 60, 79-83. doi: 10.1016/0163 1047(93)90768-D

Dearman, J., and Francis, K. T. (1983). Plasma levels of catecholamines, cortisol, and beta-endorphins in male athletes after running 26.2, 6, and 2 miles. J. Sports Med. Phys. Fitness 23, 30-38.

Decety, J., and Sommerville, J. A. (2003). Shared representations between self and other: a social cognitive neuroscience view. Trends Cogn. Sci. 7, 527-533. doi: 10.1016/j.tics.2003.10.004

Demos, A. P., Chaffin, R., Begosh, K. T., Daniels, J. R., and Marsh, K. L. (2012). Rocking to the beat: effects of music and partner's movements on spontaneous interpersonal coordination. J. Exp. Psychol. Gen. 141, 49-53. doi $10.1037 / \mathrm{a} 0023843$

Depue, R. A., and Morrone-Strupinsky, J. V. (2005). A neurobehavioral model of affiliative bonding: implications for conceptualizing a human trait of affiliation. Behav. Brain Sci. 28, 313-395. doi: 10.1017/S0140525X05 000063

Dezecache, G., and Dunbar, R. I. M. (2012). Sharing the joke: the size of natural laughter groups. Evol. Hum. Behav. 33, 775-779. doi: 10.1016/j.evolhumbehav.2012.07.002

Dishman, R. K., and O'Connor, P. J. (2009). Lessons in exercise neurobiology: the case of endorphins. Ment. Health Phys. Act. 2, 4-9. doi: 10.1016/j.mhpa.2009.01.002

Domes, G., Heinrichs, M., Michel, A., Berger, C., and Herpertz, S. C. (2007). Oxytocin improves "mind-reading" in humans. Biol. Psychiatry 61, 731-733. doi: 10.1016/j.biopsych.2006.07.015

Dumas, G., Nadel, J., Soussignan, R., Martinerie, J., and Garnero, L. (2010) Inter-brain synchronization during social interaction. PLOS ONE 5:e12166. doi 10.1371/journal.pone.0012166

Dunbar, R. I. M. (2004). "Language, music, and laughter in evolutionary perspective," in Evolution of Communication Systems: A Comparative Approach, eds D. K. Oller and U. Griebel (Cambridge, MA: MIT Press), 257-274.

Dunbar, R. I. M. (2009). "Mind the bonding gap: constraints on the evolution of hominin societies," in Pattern and Process in Cultural Evolution, ed. S. Shennan (Berkeley, CA: University of California Press), 223-234.

Dunbar, R. I. M. (2010). The social role of touch in humans and primates: behavioural function and neurobiological mechanisms. Neurosci. Biobehav. Rev. 34, 260-268. doi: 10.1016/j.neubiorev.2008. 07.001
Dunbar, R. I. M. (2012a). Bridging the bonding gap: the transition from primates to humans. Philos. Trans. R. Soc. Lond. B Biol. Sci. 367, 1837-1846. doi: $10.1098 /$ rstb.2011.0217

Dunbar, R. I. M. (2012b). "On the evolutionary function of song and dance," in Music, Language and Human Evolution, eds N. Bannan and S. Mithen (Oxford: Oxford University Press), 201-214.

Dunbar, R. I. M., Baron, R., Frangou, A., Pearce, E., Van Leeuwen, E. J. C., Stow, J. et al. (2012a). Social laughter is correlated with an elevated pain threshold. Proc. Biol. Sci. 279, 1161-1167. doi: 10.1098/rspb.2011.1373

Dunbar, R. I. M., Kaskatis, K., MacDonald, I., and Barra, V. (2012b). Performance of music elevates pain threshold and positive affect: implications for the evolutionary function of music. Evol. Psychol. 10, 688-702.

Eitan, Z., and Granot, R. Y. (2006). How music moves. Music Percept. 23, 221-248. doi: $10.1525 / \mathrm{mp} .2006 .23 .3 .221$

Fadiga, L., Craighero, L., Buccino, G., and Rizzolatti, G. (2002). Speech listening specifically modulates the excitability of tongue muscles: a TMS study. Eur. J. Neurosci. 15, 399-402. doi: 10.1046/j.0953-816x.2001. 01874.x

Fadiga, L., Fogassi, L., Pavesi, G., and Rizzolatti, G. (1995). Motor facilitation during action observation: a magnetic stimulation study. J. Neurophysiol. 73, 2608-2611.

Feldman, R. (2012). Oxytocin and social affiliation in humans. Horm. Behav. 61, 380-391. doi: 10.1016/j.yhbeh.2012.01.008

Fields, H. L. (2007). Understanding how opioids contribute to reward and analgesia. Reg. Anesth. Pain Med. 32, 242-246. doi: 10.1016/j.rapm.2007.01.001

Freeman, W. J. III. (2000). "A neurobiological role of music in social bonding," in The Origins of Music, eds N. Wallin, B. Merkur, and S. Brown (Cambridge, MA: MIT Press), 411-424.

Frijda, N., and Zeelenberg, M. (2001). "Appraisal: what is the dependent?" in Appraisal Processes in Emotion, eds R. J. Davidson, P. Ekman, and K. R. Scherer (Oxford: Oxford University Press), 141-155.

Fritz, T. H., Halfpaap, J., Grahl, S., Kirkland, A., and Villringer, A. (2013a). Musical feedback during exercise machine workout enhances mood. Front. Psychol. 4:921. doi: 10.3389/fpsyg.2013.00921

Fritz, T. H., Hardikar, S., Demoucron, M., Niessen, M., Demey, M., Giot, O., et al. (2013b). Musical agency reduces perceived exertion during strenuous physical performance. Proc. Natl. Acad. Sci. U.S.A. 110, 17784-17789. doi: 10.1073/pnas. 1217252110

Gallese, V., Fadiga, L., Fogassi, L., and Rizzolatti, G. (1996). Action recognition in the premotor cortex. Brain 119(Pt 2), 593-609. doi: 10.1093/brain/119.2.593

Gerra, G., Zaimovic, A., Franchini, D., Palladino, M., Giucastro, G., Reali, N., et al. (1998). Neuroendocrine responses of healthy volunteers to "techno-music": relationships with personality traits and emotional state. Int. J. Psychophysiol. 28, 99-111. doi: 10.1016/S0167-8760(97)00071-8

Goldstein, A. (1980). Thrills in response to music and other stimuli. Physiol. Psychol. 8, 126-129. doi: 10.3758/BF03326460

Good, M., Stanton-Hicks, M., Grass, J. A., Anderson, G. C., Lai, H. L., Roykulcharoen, V., etal. (2001). Relaxation and music to reduce postsurgical pain. J. Adv. Nurs. 33, 208-215. doi: 10.1046/j.1365-2648.2001. 01655.x

Grape, C., Sandgren, M., Hansson, L.-O., Ericson, M., and Theorell, T. (2003). Does singing promote well-being?: an empirical study of professional and amateur singers during a singing lesson. Integr. Physiol. Behav. Sci. 38, 65-74. doi: 10.1007/BF02734261

Graves, F. C., Wallen, K., and Maestripieri, D. (2002). Opioids and attachment in rhesus macaque (Macaca mulatta) abusive mothers. Behav. Neurosci. 116, 489-493 doi: 10.1037//0735-7044.116.3.489

Guastella, A. J., Mitchell, P. B., and Dadds, M. R. (2008). Oxytocin increases gaze to the eye region of human faces. Biol. Psychiatry 63, 3-5. doi: 10.1016/j.biopsych.2007.06.026

Hagen, E. H., and Bryant, G. A. (2003). Music and dance as a coalition signalling system. Hum. Nat. 14, 21-51. doi: 10.1007/s12110-003$1015-z$

Harbach, H., Hell, K., Gramsch, C., Katz, N., Hempelmann, G., and Teschemacher, H. (2000). Beta-endorphin (1-31) in the plasma of male volunteers undergoing physical exercise. Psychoneuroendocrinology 25, 551-562. doi: 10.1016/S03064530(00)00009-3

Hickok, G. (2009). Eight problems for the mirror neuron theory of action understanding in monkeys and humans. J. Cogn. Neurosci. 21, 1229-1243. doi: 10.1162/jocn.2009.21189 
Hove, M. J., and Risen, J. L. (2009). It's all in the timing: interpersonal synchrony increases affiliation. Soc. Cogn. 27, 949-961. doi: 10.1521/soco.2009. 27.6.949

Howlett, T. A., Tomlin, S., Ngahfoong, L., Rees, L. H., Bullen, B. A., Skrinar, G. S., et al. (1984). Release of beta endorphin and met-enkephalin during exercise in normal women: response to training. Br. Med. J. 288, 1950-1952. doi $10.1136 /$ bmj.288.6435.1950

Huron, D. (2001). Is music an evolutionary adaptation? Ann. N. Y. Acad. Sci. 930, 43-61. doi: 10.1111/j.1749-6632.2001.tb05724.x

Huron, D. (2006). Sweet Anticipation: Music and the Psychology of Expectation. Cambridge, MA: MIT Press.

Husain, G., Thompson, W. F., and Schellenberg, E. G. (2002). Effects of musical tempo and mode on arousal, mood, and spatial abilities. Music Percept. 20, 151171. doi: $10.1525 / \mathrm{mp} .2002 .20 .2 .151$

Insel, T. R. (2003). Is social attachment an addictive disorder? Physiol. Behav. 79, 351-357. doi: 10.1016/S0031-9384(03)00148-3

Insel, T. R. (2010). The challenge of translation in social neuroscience: a review of oxytocin, vasopressin, and affiliative behavior. Neuron 65, 768-779. doi: 10.1016/j.neuron.2010.03.005

Isen, A. M. (1970). Success, failure, attention, and reaction to others: the warm glow of success. J. Pers. Soc. Psychol. 15, 294-301. doi: 10.1037/ h0029610

Issartel, J., Marin, L., and Cadopi, M. (2007). Unintended interpersonal coordination: "can we march to the beat of our own drum?" Neurosci. Lett. 411, 174-179. doi: 10.1016/j.neulet.2006.09.086

Jamner, L. D., and Leigh, H. (1999). Repressive/defensive coping, endogenous opioids and health: how a life so perfect can make you sick. Psychiatry Res. 85, 17-31. doi: 10.1016/S0165-1781(98)00134-6

Janal, M. N., Colt, E. W., Clark, W. C., and Glusman, M. (1984). Pain sensitivity, mood and plasma endocrine levels in man following long-distance running: effects of naloxone. Pain 19, 13-25. doi: 10.1016/0304-3959(84)90061-7

Janata, P., and Grafton, S. T. (2003). Swinging in the brain: shared neural substrates for behaviors related to sequencing and music. Nat. Neurosci. 6, 682-687. doi: $10.1038 / \mathrm{nn} 1081$

Janata, P., Tomic, S. T., and Haberman, J. M. (2012). Sensorimotor coupling in music and the psychology of the groove. J. Exp. Psychol. Gen. 141, 54-75. doi: 10.1037/a0024208

Jones, M. R., and Boltz, M. (1989). Dynamic attending and responses to time. Psychol. Rev. 96, 459-491. doi: 10.1037/0033-295X.96.3.459

Karageorghis, C. I., and Terry, P. C. (2009). "The psychological, psychophysical, and ergogenic effects of music in sport: a review and synthesis," in Sporting Sounds: Relationships Between Sport and Music, eds A. Bateman and J. Bale (London: Routeledge), 13-36.

Keverne, E. B., Martensz, N. D., and Tuite, B. (1989). Beta-endorphin concentrations in cerebrospinal fluid of monkeys are influenced by grooming relationships. Psychoneuroendocrinology 14, 155-161. doi: 10.1016/0306-4530(89) 90065-6

Kirschner, S., and Tomasello, M. (2009). Joint drumming: social context facilitates synchronization in preschool children. J. Exp. Child Psychol. 102, 299-314. doi: 10.1016/j.jecp.2008.07.005

Knoblich, G., and Sebanz, N. (2008). Evolving intentions for social interaction: from entrainment to joint action. Philos. Trans. R. Soc. Lond. B Biol. Sci. 363 2021-2031. doi: 10.1098/rstb.2008.0006

Koch, M. E., Kain, Z. N., Ayoub, C., and Rosenbaum, S. H. (1998). The sedative and analgesic sparing effect of music. Anesthesiology 89, 300-306. doi: 10.1097/00000542-199808000-00005

Koelsch, S. (2010). Towards a neural basis of music-evoked emotions. Trends Cogn. Sci. 14, 131-137. doi: 10.1016/j.tics.2010.01.002

Koelsch, S. (2014). Brain correlates of music-evoked emotions. Nat. Rev. Neurosci. 15, 170-180. doi: 10.1038/nrn3666

Koepp, M. J., Hammers, A., Lawrence, A. D., Asselin, M. C., Grasby, P. M., and Bench, C. J. (2009). Evidence for endogenous opioid release in the amygdala during positive emotion. Neuroimage 44, 252-256. doi: 10.1016/j.neuroimage.2008. 08.032

Kokal, I., Engel, A., Kirschner, S., and Keysers, C. (2011). Synchronized drumming enhances activity in the caudate and facilitates prosocial commitment-if the rhythm comes easily. PLoS ONE 6:e27272. doi: 10.1371/journal.pone.00 27272
Koob, G. F. (1992). Drugs of abuse: anatomy, pharmacology and function of reward pathways. Trends Pharmacol. Sci. 13, 177-184. doi: 10.1016/0165-6147(92)9 0060-J

Kosfeld, M., Heinrichs, M., Zak, P. J., Fischbacher, U., and Fehr, E. (2005). Oxytocin increases trust in humans. Nature 435, 673-676. doi: 10.1038/nature03701

Kuhn, D. (2002). The effects of active and passive participation in musical activity on the immune system as measured by salivary immunoglobulin a (siga). J. Music Ther. 39, 30-39. doi: 10.1093/jmt/39.1.30

LaFrance, M. (1979). Nonverbal synchrony and rapport: analysis by the cross-lag panel technique. Soc. Psychol. Q. 42, 66-70. doi: 10.2307/3033875

LaFrance, M., and Broadbent, M. (1976). Group rapport: posture sharing as a nonverbal indicator. Group Organ. Stud. 1, 328-333. doi: $10.1177 / 105960117600100307$

Lakens, D., and Stel, M. (2011). If they move in sync, they must feel in sync: movement synchrony leads to attributions of rapport and entitativity. Soc. Cogn. 29, 1-14. doi: 10.1521/soco.2011.29.1.1

Lakin, J. L., and Chartrand, T. L. (2003). Using nonconscious behavioral mimicry to create affiliation and rapport. Psychol. Sci. 14, 334-339. doi: 10.1111/14679280.14481

Launay, J., Dean, R. T., and Bailes, F. (2013). Synchronization can influence trust following virtual interaction. Exp. Psychol. 60, 53-63. doi: 10.1027/16183169/a000173

Launay, J., Dean, R. T., and Bailes, F. (2014). Synchronising movements with the sounds of a virtual partner enhances partner likeability. Cogn. Process. doi: 10.1007/s10339-014-0618-0 [Epub ahead of print].

Leknes, S., and Tracey, I. (2008). A common neurobiology for pain and pleasure. Nat. Rev. Neurosci. 9, 314-320. doi: 10.1038/nrn2333

Lepage, C., Drolet, P., Girard, M., Grenier, Y., and De Gagné, R. (2001). Music decreases sedative requirements during spinal anesthesia. Anesth. Analg. 93, 912916. doi: 10.1097/00000539-200110000-00022

Levitin, D. J., and Menon, V. (2003). Musical structure is processed in "language" areas of the brain: a possible role for Brodmann Area 47 in temporal coherence. Neuroimage 20, 2142-2152. doi: 10.1016/j.neuroimage.2003.08.016

Levitin, D. J., and Tirovolas, A. K. (2009). Current advances in the cognitive neuroscience of music. Ann. N. Y. Acad. Sci. 1156, 211-231. doi: 10.1111/j.1749-6632.2009.04417.x

Lindenberger, U., Li, S.-C., Gruber, W., and Müller, V. (2009). Brains swinging in concert: cortical phase synchronization while playing guitar. BMC Neurosci. 10:22. doi: 10.1186/1471-2202-10-22

Lumsden, J., Miles, L. K., Richardson, M. J., Smith, C. A., and Macrae, C. N. (2012). Who syncs? Social motives and interpersonal coordination. J. Exp. Soc. Psychol. 48, 746-751. doi: 10.1016/j.jesp.2011.12.007

Machin, A. J., and Dunbar, R. I. M. (2011). The brain opioid theory of social attachment: a review of the evidence. Behaviour 148, 985-1025. doi: $10.1163 / 000579511$ X596624

Madison, G. S. (2006). Experiencing groove induced by music: consistency and phenomenology. Music Percept. Interdiscip. J. 24, 201-208. doi: 10.1525/mp.2006.24.2.201

Madison, G. S., Gouyon, F., Ullén, F., and Hörnström, K. (2011). Modeling the tendency for music to induce movement in humans: first correlations with lowlevel audio descriptors across music genres. J. Exp. Psychol. Hum. Percept. Perform. 37, 1578-1594. doi: 10.1037/a0024323

Margulis, E. H. (2013). On Repeat: How Music Plays the Mind. New York: Oxford University Press.

Marsh, K. L., Richardson, M. J., and Schmidt, R. C. (2009). Social connection through joint action and interpersonal coordination. Top. Cogn. Sci. 1, 320-339. doi: 10.1111/j.1756-8765.2009.01022.x

Martel, F. L., Nevison, C. M., Rayment, D., Simpson, M. J., and Keverne, E. B. (1993). Opioid receptor blockade reduces maternal affect and social grooming in rheses monkeys. Psychoneuroendocrinology 18, 307-321. doi: 10.1016/03064530(93)90027-I

Martel, F. L., Nevison, C. M., Simpson, M. J., and Keverne, E. B. (1995). Effects of opioid receptor blockade on the social behavior of rhesus monkeys living in large family groups. Dev. Psychobiol. 28, 71-84. doi: 10.1002/dev.420280202

Matthes, H. W. D., Maldonado, R., Simonin, F., Valverde, O., Slowe, S., Kitchen, I., et al. (1996). Loss of morphine-induced analgesia, reward effect and withdrawal symptoms in mice lacking the mu-opioid-receptor gene. Nature 383, 819-823. doi: $10.1038 / 383819 \mathrm{a} 0$ 
McDermott, J. (2008). The evolution of music. Nature 453, 287-288. doi: $10.1038 / 453287 \mathrm{a}$

McKinney, C. H., Antoni, M. H., Kumar, M., Rims, F. C., and McCabe, P. M. (1997a). Effects of guided imagery and music (GIM) therapy on mood and cortisol in healthy adults. Health Psychol. 16, 390-400. doi: 10.1037/0278-6133.16.4.390

McKinney, C. H., Tims, F. C., Kumar, A. M., and Kumar, M. (1997b). The effect of selected classical music and spontaneous imagery on plasma beta-endorphin. J. Behav. Med. 20, 85-99. doi: 10.1023/A:1025543330939

McNeill, W. H. (1995). Keeping Together in Time. Cambridge, MA: Harvard University Press.

Menon, V., and Levitin, D. J. (2005). The rewards of music listening: response and physiological connectivity of the mesolimbic system. Neuroimage 28, 175-184. doi: 10.1016/j.neuroimage.2005.05.053

Merker, B. (2000). "Synchronous chorusing and human origins," in The Origins of Music, eds N. Wallin, B. H. Merker, and S. Brown (Cambridge, MA: MIT Press), 315-327.

Merker, B., Madison, G. S., and Eckerdal, P. (2009). On the role and origin of isochrony in human rhythmic entrainment. Cortex 45, 4-17. doi: 10.1016/j.cortex.2008.06.011

Meyer-Lindenberg, A., Domes, G., Kirsch, P., and Heinrichs, M. (2011). Oxytocin and vasopressin in the human brain: social neuropeptides for translational medicine. Nat. Rev. Neurosci. 12, 524-538. doi: 10.1038/ nrn3044

Miles, L. K., Griffiths, J. L., Richardson, M. J., and Macrae, C. N. (2010). Too late to coordinate: contextual influences on behavioral synchrony. Eur. J. Soc. Psychol. 40, 52-60. doi: 10.1002/ejsp.721

Miles, L. K., Lumsden, J., Richardson, M. J., and Neil Macrae, C. (2011). Do birds of a feather move together? Group membership and behavioral synchrony. Exp. Brain Res. 211, 495-503. doi: 10.1007/s00221-0112641-z

Miles, L. K., Nind, L. K., and Macrae, C. N. (2009). The rhythm of rapport: interpersonal synchrony and social perception. J. Exp. Soc. Psychol. 45, 585-589. doi: 10.1016/j.jesp.2009.02.002

Miller, G. F. (2000). The Mating Mind: How Sexual Choice Shaped the Evolution of the Human Nature. New York, NY: Random House Inc.

Moles, A., Kieffer, B. L., and D'Amato, F. R. (2004). Deficit in attachment behavior in mice lacking the mu-opioid receptor gene. Science 304, 1983-1986. doi: $10.1126 /$ science. 1095943

Mueller, C., Klega, A., Buchholz, H.-G., Rolke, R., Magerl, W., Schirrmacher, R., etal. (2010). Basal opioid receptor binding is associated with differences in sensory perception in healthy human subjects: a [18F]diprenorphine PET study. Neuroimage 49, 731-737. doi: 10.1016/j.neuroimage.2009. 08.033

Mueller, F., Agamanolis, S., and Picard, R. (2003). "Exertion interfaces: sports over a distance for social bonding and fun," in Proceedings of the SIGCHI Conference on Human Factors in Computing Systems, Lauderdale, FL.

Nettl, B. (1983). The Study of Ethnomusicology: Twenty-Nine Issues and Concepts. Urbana, IL: University of Illinois Press.

Nettl, B. (2000). "An ethnomusicologist contemplates universals in musical sound and musical culture," in The Origins of Music, eds N. L. Wallin, B. Merker, and S. Brown (Cambridge, MA: MIT Press), 463-472.

Nilsson, U. (2008). Effects of music interventions: a systematic review. AORN J. 87, 780-807. doi: 10.1016/j.aorn.2007.09.013

Nilsson, U., Rawal, N., Enqvist, B., and Unosson, M. (2003). Analgesia following music and therapeutic suggestions in the PACU in ambulatory surgery a randomized controlled trial. Acta Anaesthesiol. Scand. 47, 278-283. doi: 10.1034/j.1399-6576.2003.00064.x

Nilsson, U., Rawal, N., Uneståhl, L. E., Zetterberg, C., and Unosson, M. (2001). Improved recovery after music and therapeutic suggestions during general anaesthesia: a double-blind randomised controlled trial. Acta Anaesthesiol. Scand. 45, 812-817. doi: 10.1034/j.1399-6576.2001. 045007812.x

Olmstead, M. C., and Franklin, K. B. (1997). The development of a conditioned place preference to morphine: effects of lesions of various CNS sites. Behav. Neurosci. 111, 1313-1323. doi: 10.1037/0735-7044.111.6.1313

Oullier, O., De Guzman, G. C., Jantzen, K. J., Lagarde, J., and Kelso, J. A S. (2008). Social coordination dynamics: measuring human bonding. Soc. Neurosci. 3, 178 192. doi: 10.1080/17470910701563392
Oullier, O., Jantzen, K. J., Steinberg, F. L., and Kelso, J. A S. (2005). Neural substrates of real and imagined sensorimotor coordination. Cereb. Cortex 15, 975-985. doi: 10.1093/cercor/bhh198

Overy, K., and Molnar-Szakacs, I. (2009). Being together in time: musical experience and the mirror neuron system. Music Percept. 26, 489-504. doi: 10.1525/mp.2009.26.5.489

Panksepp, J. (1995). The emotional sources of "chills" induced by music. Music Percept. Interdiscip. J. 13, 171-207. doi: 10.2307/40285693

Panksepp, J., Herman, B. H., Vilberg, T., Bishop, P., and De Eskinazi, F. G. (1980). Endogenous opioids and social behavior. Neurosci. Biobehav. Rev. 4, 473-487. doi: 10.1016/0149-7634(80)90036-6

Peters, D. (2010). Enactment in listening: intermedial dance in EGM sonic scenarios and the bodily grounding of the listening experience. Perform. Res. 15:3. doi: $10.1080 / 13528165.2010 .527211$

Pinker, S. (1997). How the Mind Works. New York: Norton.

Ragen, B. J., Maninger, N., Mendoza, S. P., Jarcho, M. R., and Bales, K. L. (2013). Presence of a pair-mate regulates the behavioral and physiological effects of opioid manipulation in the monogamous titi monkey (Callicebus cupreus). Psychoneuroendocrinology 38, 2448-2461. doi: 10.1016/j.psyneuen.2013. 05.009

Reddish, P., Fischer, R., and Bulbulia, J. (2013). Let's dance together: synchrony, shared intentionality and cooperation. PLOS ONE 8:e71182. doi: 10.1371/journal.pone.0071182

Reddy, V. (2003). On being the object of attention: implications for self-other consciousness. Trends Cogn. Sci. 7, 397-402. doi: 10.1016/S1364-6613(03) 00191-8

Resendez, S. L., Dome, M., Gormley, G., Franco, D., Nevárez, N., Hamid, A. A., et al. (2013). $\mu$-Opioid receptors within subregions of the striatum mediate pair bond formation through parallel yet distinct reward mechanisms. J. Neurosci. 33, 9140-9149. doi: 10.1523/JNEUROSCI.4123-12.2013

Rizzolatti, G. (2005). The mirror neuron system and its function in humans. Anat. Embryol. (Berl.) 210, 419-421. doi: 10.1007/s00429-005-0039-Z

Rizzolatti, G., Fadiga, L., Gallese, V., and Fogassi, L. (1996). Premotor cortex and the recognition of motor actions. Brain Res. Cogn. Brain Res. 3, 131-141. doi: 10.1016/0926-6410(95)00038-0

Roederer, J. G. (1984). The search for a survival value of music. Music Percept. 1, 350-356. doi: 10.2307/40285265

Salimpoor, V. N., Benovoy, M., Larcher, K., Dagher, A., and Zatorre, R. J. (2011). Anatomically distinct dopamine release during anticipation and experience of peak emotion to music. Nat. Neurosci. 14, 257-262. doi: 10.1038/ nn. 2726

Savaskan, E., Ehrhardt, R., Schulz, A., Walter, M., and Schächinger, H. (2008). Post-learning intranasal oxytocin modulates human memory for facial identity. Psychoneuroendocrinology 33, 368-374. doi: 10.1016/j.psyneuen.2007.12.004

Schino, G., and Troisi, A. (1992). Opiate receptor blockade in juvenile macaques: effect on affiliative interactions with their mothers and group companions. Brain Res. 576, 125-130. doi: 10.1016/0006-8993(92)90617-I

Sebanz, N., Bekkering, H., and Knoblich, G. (2006). Joint action: bodies and minds moving together. Trends Cogn. Sci. 10, 70-76. doi: 10.1016/j.tics.2005. 12.009

Sievers, B., Polansky, L., Casey, M., and Wheatley, T. (2013). Music and movement share a dynamic structure that supports universal expressions of emotion. Proc. Natl. Acad. Sci. U.S.A. 110, 70-75. doi: 10.1073/pnas.1209023110

Sommerville, J. A., and Decety, J. (2006). Weaving the fabric of social interaction: articulating developmental psychology and cognitive neuroscience in the domain of motor cognition. Psychon. Bull. Rev. 13, 179-200. doi: 10.3758/BF03193831

Stefano, G. B., Zhu, W., Cadet, P., Salamon, E., and Mantione, K. J. (2004). Music alters constitutively expressed opiate and cytokine processes in listeners. Med. Sci. Monit. 10, MS18-MS27.

Stel, M., Blascovich, J., Mccall, C., Mastop, J., Van baaren, R. B., and Vonk, R. (2010). Mimicking disliked others: effects of a priori liking on the mimicry-liking link. Eur. J. Soc. Psychol. 40, 867-880. doi: 10.1002/ejsp.655

Sullivan, P., and Rickers, K. (2013). The effect of behavioral synchrony in groups of teammates and strangers. Int. J. Sport Exerc. Psychol. 11, 286-291. doi: 10.1080/1612197X.2013.750139

Sullivan, P. J., Rickers, K., and Gammage, K. L. (2014). The effect of different phases of synchrony on pain threshold. Gr. Dyn. 18, 122-128. doi: 10.1037/ gdn0000001 
Thayer, R. E., Newman, J. R., and Mcclain, T. M. (1994). Self-regulation selfregulation of mood: strategies for changing a bad mood, raising energy, and reducing tension search. J. Pers. Soc. Psychol. 64, 910-925. doi: 10.1037/00223514.67.5.910

Tognoli, E., Lagarde, J., De Guzman, G. C., and Kelso, J. A S. (2007). The phi complex as a neuromarker of human social coordination. Proc. Natl. Acad. Sci. U.S.A. 104 8190-8195. doi: 10.1073/pnas.0611453104

Tomasello, M., Carpenter, M., Call, J., Behne, T., and Moll, H. (2005). Understanding and sharing intentions: the origins of cultural cognition. Behav. Brain Sci. 28 675-691; discussion 691-735. doi: 10.1017/S0140525X05000129

Trigo, J. M., Martin-García, E., Berrendero, F., Robledo, P., and Maldonado, R. (2010). The endogenous opioid system: a common substrate in drug addiction. Drug Alcohol Depend. 108, 183-194. doi: 10.1016/j.drugalcdep.2009.10.011

Valdesolo, P., and Desteno, D. (2011). Synchrony and the social tuning of compassion. Emotion 11, 262-266. doi: 10.1037/a0021302

Van Baaren, R. B., Holland, R. W., Kawakami, K., and Van Knippenberg, A. (2004). Mimicry and prosocial behavior. Psychol. Sci. 15, 71-74. doi: 10.1111/j.09637214.2004.01501012.x

Van Ree, J. M., Niesink, R. J., Van Wolfswinkel, L., Ramsey, N. F., Kornet, M. M., Van Furth, W. R., et al. (2000). Endogenous opioids and reward. Eur. J. Pharmacol. 405, 89-101. doi: 10.1016/S0014-2999(00)00544-6

van Ulzen, N. R., Lamoth, C. J. C., Daffertshofer, A., Semin, G. R., and Beek, P. J. (2008). Characteristics of instructed and uninstructed interpersonal coordination while walking side-by-side. Neurosci. Lett. 432, 88-93. doi: 10.1016/i.neulet.2007.11.070

Wiltermuth, S. S. (2012). Synchronous activity boosts compliance with requests to aggress. J. Exp. Soc. Psychol. 48, 453-456. doi: 10.1016/j.jesp.2011.10.007

Wiltermuth, S. S., and Heath, C. (2009). Synchrony and cooperation. Psychol. Sci. 20, 1-5. doi: 10.1111/j.1467-9280.2008.02253.x

Zak, P. J., Kurzban, R., and Matzner, W. T. (2005). Oxytocin is associated with human trustworthiness. Horm. Behav. 48, 522-527. doi: 10.1016/j.yhbeh.2005.07.009
Zak, P. J., Stanton, A. A., and Ahmadi, S. (2007). Oxytocin increases generosity in humans. PLoS ONE 2:e1128. doi: 10.1371/journal.pone.0001128

Zillmann, D., Rockwell, S., Schweitzer, K., and Sundar, S. S. (1993). Does humor facilitate coping with physical discomfort? Motiv. Emot. 17, 1-21. doi: 10.1007/BF00995204

Zubieta, J.-K., Ketter, T. A., Bueller, J. A., Xu, Y., Kilbourn, M. R., Young, E. A., et al. (2003). Regulation of human affective responses by anterior cingulate and limbic mu-opioid neurotransmission. Arch. Gen. Psychiatry 60, 1145-1153. doi: 10.1001/archpsyc.60.11.1145

Zubieta, J. K., Smith, Y. R., Bueller, J. A., Xu, Y., Kilbourn, M. R., Jewett, D. M., et al. (2001). Regional mu opioid receptor regulation of sensory and affective dimensions of pain. Science 293, 311-315. doi: 10.1126/science. 1060952

Conflict of Interest Statement: The authors declare that the research was conducted in the absence of any commercial or financial relationships that could be construed as a potential conflict of interest.

Received: 01 June 2014; accepted: 10 September 2014; published online: 30 September 2014.

Citation: Tarr B, Launay J and Dunbar RIM (2014) Music and social bonding: "self-other" merging and neurohormonal mechanisms. Front. Psychol. 5:1096. doi: $10.3389 / f p s y g .2014 .01096$

This article was submitted to Auditory Cognitive Neuroscience, a section of the journal Frontiers in Psychology.

Copyright (c) 2014 Tarr, Launay and Dunbar. This is an open-access article distributed under the terms of the Creative Commons Attribution License (CC BY). The use, distribution or reproduction in other forums is permitted, provided the original author(s) or licensor are credited and that the original publication in this journal is cited, in accordance with accepted academic practice. No use, distribution or reproduction is permitted which does not comply with these terms. 